Supporting Information

\title{
Response and Implication of NASICON Solid-State Electrolytes to Local Electrical Stimulation: from Surface Engineering to Interfacial Manipulation
}

\author{
Qiaomei Sun, ${ }^{1}$ Jin An Sam Oh, $,{ }^{1,2,3} \mathrm{Li} \mathrm{Lu},{ }^{1}$ Kaiyang Zeng ${ }^{1 *}$ \\ ${ }^{1}$ Department of Mechanical Engineering, National University of Singapore, 9 Engineering Drive \\ 1, Singapore 117576 \\ ${ }^{2}$ Graduate School for Integrative Sciences and Engineering, National University of Singapore, \\ Singapore 138632 \\ ${ }^{3}$ Singapore Institute of Manufacturing Technology, A*STAR (Agency for Science, Technology \\ and Research), 2 Fusionopolis Way, Innovis, Singapore 138634
}

*Corresponding author: Prof. K.Y.Zeng, National University of Singapore (mpezk@nus.edu.sg) 


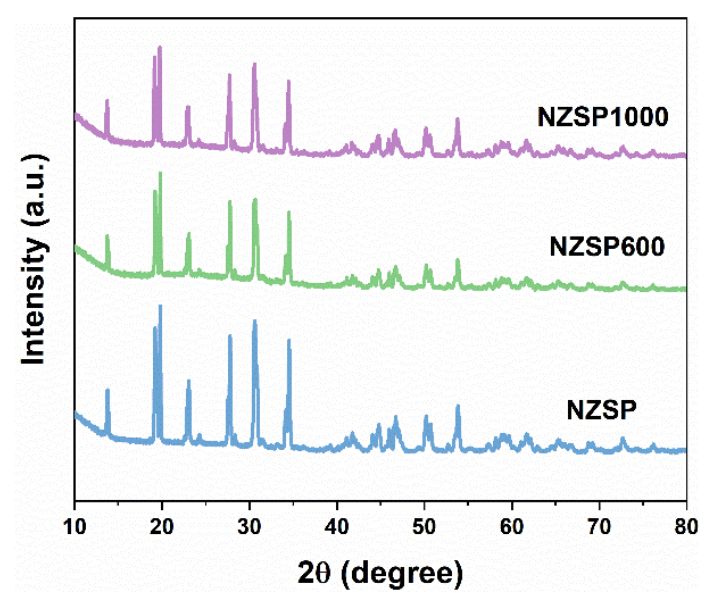

Figure S1. XRD patterns of NZSP samples after different treatments (non-reitveld analysis).
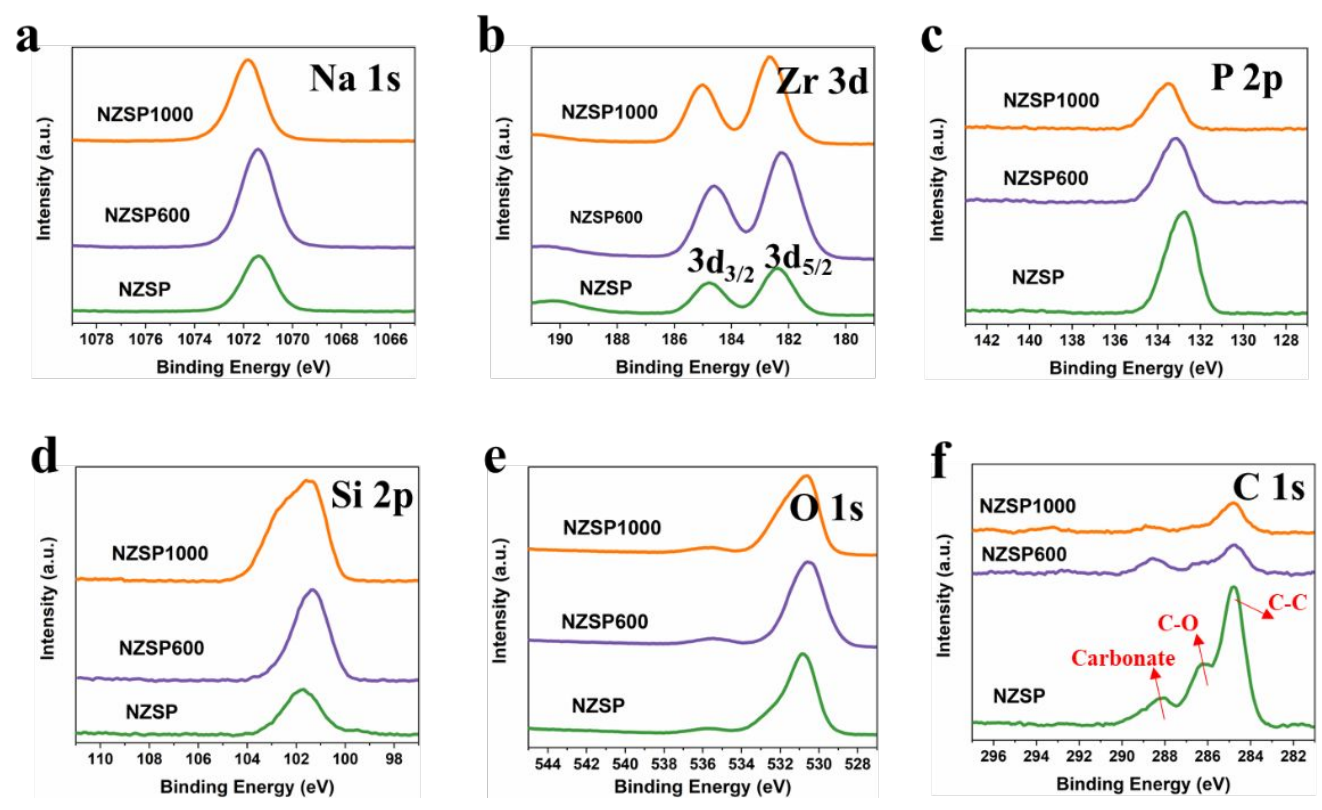

Figure S2. High resolution XPS spectra of the elements in the NZSP samples. (a) Na 1s, (b) Zr 3d, (c) P 2p, (d) Si 2p, (e) O 1s, and (f) C 1s. 

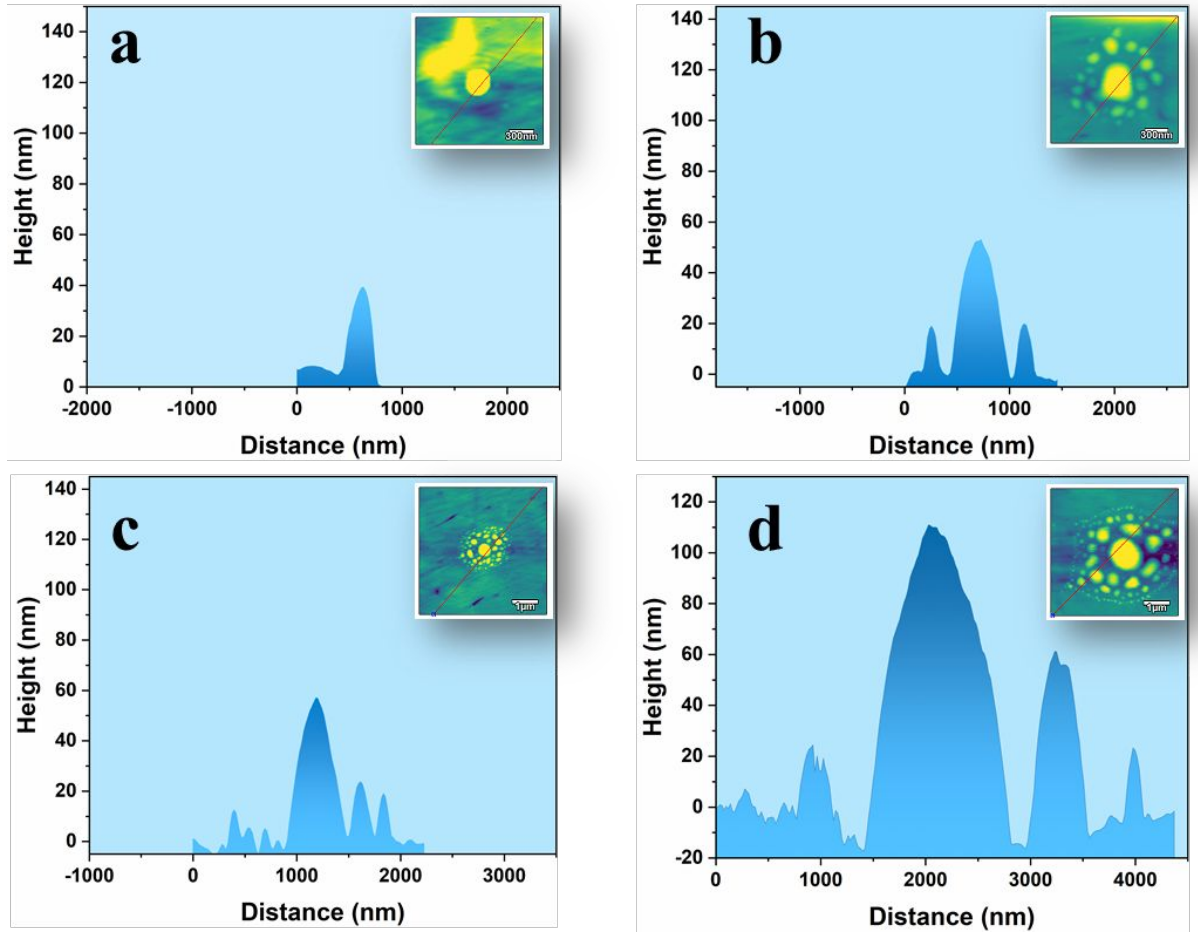

Figure S3. Line section profiles of the particles formed on the surface of the NZSP samples after $\mathrm{I}-\mathrm{V}$ measurement with the maximum voltage of (a) $1.8 \mathrm{~V}$, (b) $2.0 \mathrm{~V}$, (c) $2.2 \mathrm{~V}$, and (d) $2.5 \mathrm{~V}$. Insect images show the line section on the SPM topography images.

a

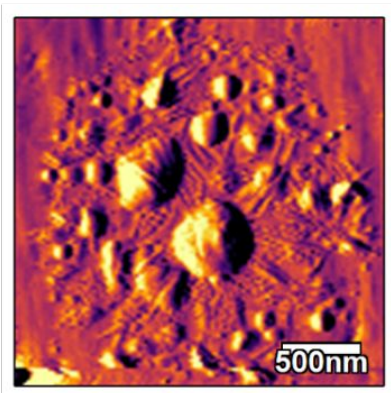

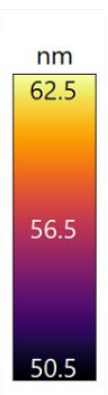
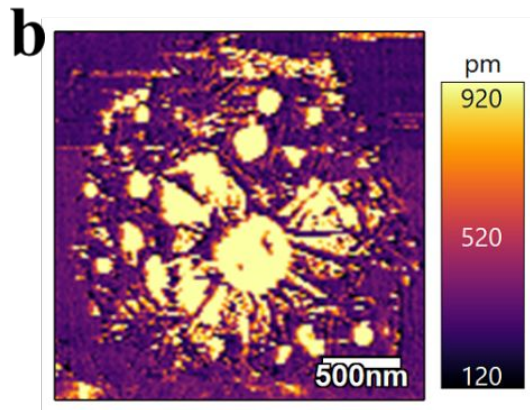

Figure S4. Bimodal images of the products formed on NZSP sample at a bias of 2.2 V. (a) First eigenmode amplitude, and (b) second eigenmode amplitude. The first eigenmode shows the cantilever feedback signal related to topography, while the second eigenmode amplitude shows contrast in the material composition. 

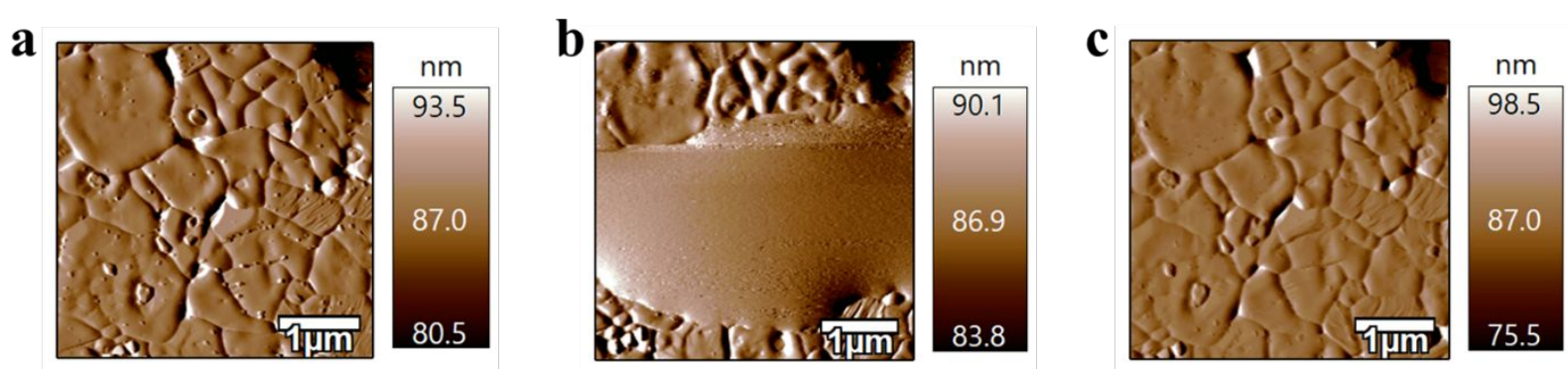

Figure S5. Topography evolution of NZSP1000 sample. (a) pristine surface, (b) the probed topography immediately after the $\mathrm{I}-\mathrm{V}$ measurement at $2 \mathrm{~V}$, and (c) the final topography after resting for $2 \mathrm{~min}$.

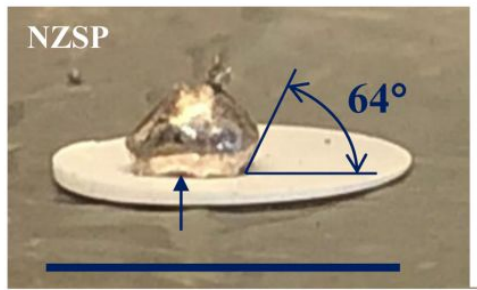

$\mathrm{CA}=116^{\circ} \mathrm{C}$

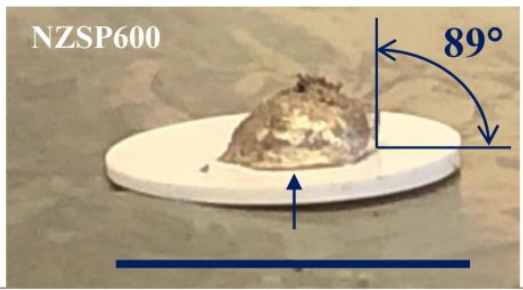

$\mathrm{CA}=91^{\circ} \mathrm{C}$

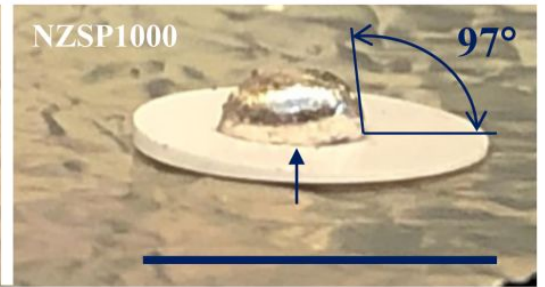

$\mathrm{CA}=83{ }^{\circ} \mathrm{C}$

Figure S6. The sodium wettability of NSZP, NZSP600 and NZSP1000 evaluated by the contact angle measurement. The measurement is conducted in the glovebox with the inert gas environment. 

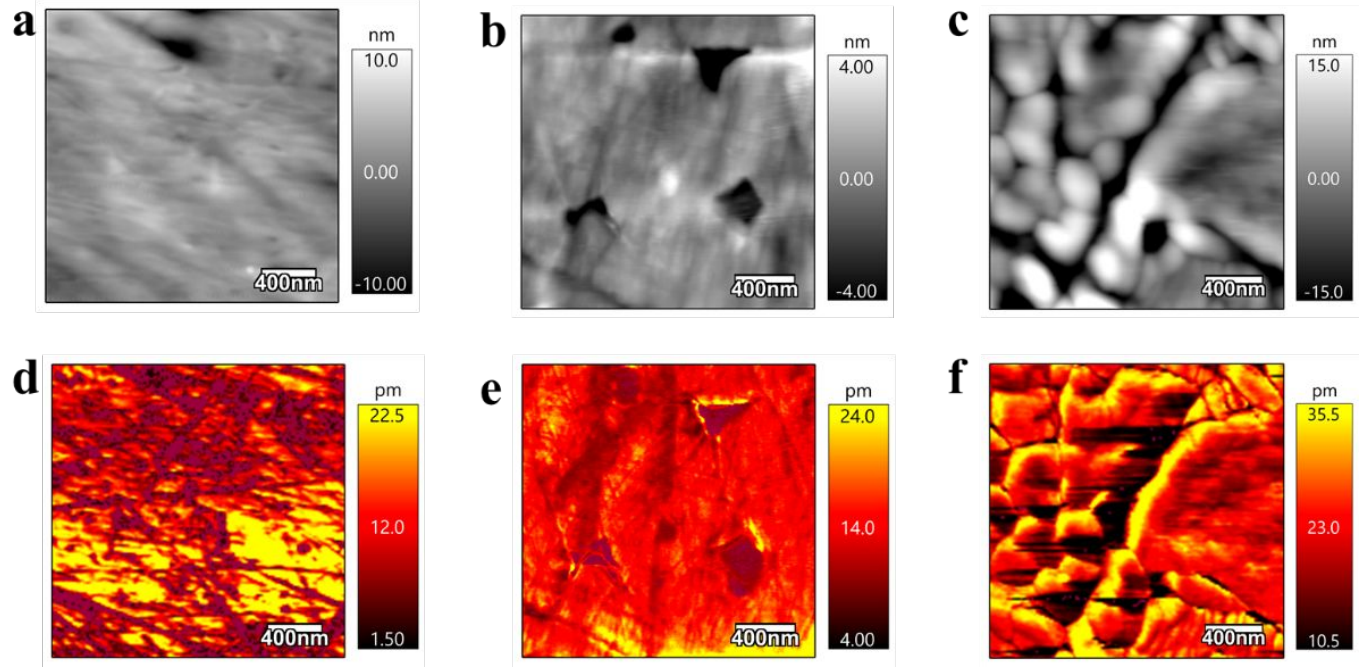

e
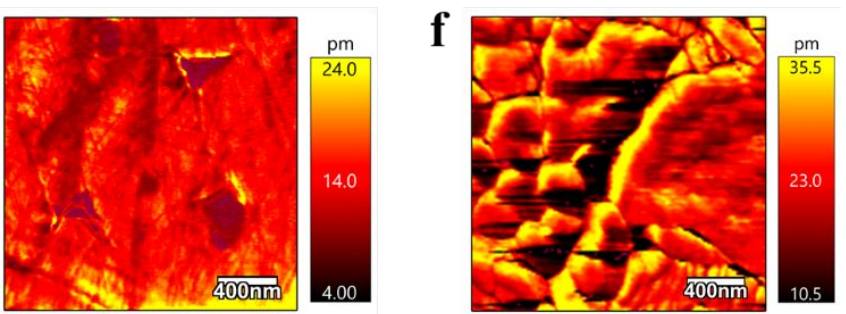

Figure S7. Local ionic dynamics of the surface. Topography of (a) NZSP, (b) NZSP600, and (c) NZSP1000 samples. ESM amplitude of (d) NZSP, (e) NZSP600, and (f) NZSP1000 samples.

Table S1. The peak current at the maximum voltage of I-V measurement in NZSP, NZSP600, and ZNSP1000 samples.

\begin{tabular}{lrrrrr}
\hline Sample & $1.5 \mathrm{~V}$ & $1.8 \mathrm{~V}$ & $2.0 \mathrm{~V}$ & $2.2 \mathrm{~V}$ & $2.5 \mathrm{~V}$ \\
\hline NZSP & & $19 \mathrm{pA}$ & $273.5 \mathrm{pA}$ & $671.6 \mathrm{pA}$ & $1.75 \mathrm{nA}$ \\
NZSP600 & $38.6 \mathrm{pA}$ & $80.3 \mathrm{pA}$ & $1.1 \mathrm{nA}$ & $29.7 \mathrm{nA}$ & $276.7 \mathrm{nA}$ \\
NZSP1000 & $32 \mathrm{pA}$ & $93.4 \mathrm{pA}$ & $6.61 \mathrm{nA}$ & $85.6 \mathrm{nA}$ & $593.8 \mathrm{nA}$ \\
& & & & & \\
\hline
\end{tabular}

